\title{
POWER SYSTEM REACTIVE COMPENSATION: EVALUATION OF EXPANSION PLANS TAKING INTO ACCOUNT ELECTROMAGNETIC TRANSIENT RESTRICTIONS
}

\author{
Fabrício Silveira Chaves*
}

\author{
Maria Helena Murta Vale*
}

\author{
*LRC - Lightning Research Center / UFMG \\ Antônio Carlos Avenue 6627 - Pampulha \\ CEP 31.270-901 - Belo Horizonte - MG - Brazil
}

\section{RESUMO}

Neste artigo, os autores apresentam seus desenvolvimentos atuais sobre Compensação Reativa Shunt Capacitiva e Controle de Tensão, no contexto do Planejamento da Expansão, considerando estudos de transitórios eletromagnéticos. $\mathrm{O}$ montante e localização da compensação reativa a ser instalada na rede elétrica é definido considerando muitos aspectos como otimização da potência reativa, cálculos de curtocircuito, estabilidade de tensão, análises de harmônicos, entre outros. Diferentes alternativas devem ser avaliadas, considerando seus impactos (positivos e negativos) no comportamento do sistema, a fim de selecionar a compensação mais adequada. O processo de decisão da expansão normalmente não inclui estudos sobre o impacto dos transitórios eletromagnéticos causados pelo chaveamento da compensação reativa shunt. Tradicionalmente, isto é feito somente depois da definição do plano de expansão, ao se elaborar o projeto detalhado - fase em que se especificam os equipamentos a serem utilizados. Neste artigo, é proposto um procedimento novo que inclui uma avaliação técnica de diferentes compensações shunt baseado numa verificação prévia dos valores de sobretensão e sobrecorrente causados pelo chaveamento de bancos de capacitores. A nova metodologia é dividida em dois principais passos: (i) indicar as barras críticas do sistema que devem ser investigadas detalhadamente, considerando o comportamento transitório; e (ii) escolher a compensação shunt

Artigo submetido em 01/02/2008 (Id:856)

Revisado em 01/09/2008 e em 14/11/2008

Aceito sob recomendação do Ed.Assoc. Prof. Julio Cesar Stacchini Souza mais adequada. O procedimento proposto é explicado com detalhes e são apresentados os resultados de sua aplicação em um sistema real.

PALAVRAS-CHAVE: Compensação Reativa Shunt Capacitiva, Controle de Tensão, Transitórios Eletromagnéticos, Avaliação Técnica, Chaveamento de Capacitores.

\section{ABSTRACT}

In this paper, the authors present developments regarding Power System Capacitive Shunt Reactive Compensation and Voltage Control, with respect to Expansion Activities, in an Electromagnetic Transient context. The definition of the amount and location of shunt reactive compensation to be installed in power systems considers several aspects, as reactive power optimization, short circuit calculations, voltage stability and harmonic analyses, among others. Different alternatives must be evaluated, regarding their impact (positive and negative) to system behavior, in order to select the most adequate compensation. Expansion decision process usually does not include studies about the transient impact of reactive shunt compensation caused by switching operation. Traditionally, this is done only after expansion definition, when the detailed project is elaborated, mainly to prepare equipment specifications. In this paper, it is proposed an innovative procedure to include a technical evaluation of different shunt compensation based on a preview of the overvoltage and overcurrent values caused by the corresponding capacitors bank switching. The new methodology is designed to 
(i) indicate the critical system buses that must be carefully investigated, considering transient behavior, and (ii) promote the adequate shunt compensation adjust. The proposed procedure is detailed and results of its application in real systems are presented.

KEYWORDS: Capacitive Shunt Reactive Compensation, Voltage Control, Electromagnetic Transients, Technical Evaluation, Capacitor Switching.

\section{INTRODUCTION}

Power System Planning activities involve the analysis of several and different expansion alternatives. Capacitive Shunt Reactive Compensation (RC) appears as one of the most adopted due to its relevant benefits for system behavior. Optimization of reactive power flow, voltage control, reduction of system losses and power factor adjustment are some of these benefits. Besides, reactive compensation is very attractive regarding economic aspects.

Traditionally, planners staff identifies the amount and location of RC equipment based on reactive power flow and injection optimization. Several system conditions are investigated considering different operative states (normal, restorative and emergency), in order to decide about the RC to be adopted.

The optimal power flow calculation has been the basic tool used to prepare expansion plans. The formulation involves the selection of specific objective functions and restrictions to be obeyed. A greater and better exploitation of system resources is expected considering cost minimization. Regarding reactive compensation, objective functions commonly used refers to the minimization of the reactive power flow in system network, the reactive power injection to be installed, the reactive and active losses, and the costs of acquisition, maintenance and operation of the equipment to be placed. Such objectives must be reached without violating technical, economic, security, legislation, social and ambient restrictions. The RC plan must provide an adequate voltage control. This optimization process has been explored by the authors as described in Chaves (2001) and in Chaves and Vale (2002).

The consideration of all aspects mentioned above characterizes a complex problem to be solved by planners. In fact, the decision process involves specific procedures that guide plans preparation. The methodology developed and adopted by the authors considers the following steps: (i) Power System Diagnosis Evaluation, in order to detect any deficiency; (ii) RC Equipment Definition - one or more alternatives are usually generated by some optimization process; (iii) Economical and Technical Evaluation of the alternatives; (iv)
Selection of the most adequate alternative and Preparation of the Expansion Plan to be adopted. It is important to emphasize that these steps indicate the RC amount and location. After them, project activities take place, where all equipment are specified in details.

All steps of the decision process identified above are treated in details by the authors in reference Chaves (2007). The optimization process proposed in this reference, step (ii), has been successfuly applied in real system planning strategies, to identify RC alternatives (Chaves and Vale, 2002). The relevance of the technical evaluation step (iii) is emphasized, because it is responsible for the analysis of the influence of the suggested RC equipment in system behavior. Depending on the results of these analyses, the planning RC proposals may be adjusted or even neglected.

In addition to the commonly studies prepared in this stage, the authors developed special procedures to evaluate the impact of shunt compensation on system voltage stability (Vale, 2005), harmonic distortion and electromagnetic transients. The present work is dedicated to the electromagnetic studies.

As known, shunt capacitors switching can result in significant overvoltage and overcurrent in power systems. Depending on the magnitudes of these transients and on system damping, the capacitor bank and other equipment in its vicinity can be damaged (Coury et alii, 1998; McGranaghan et alii, 1992; Surge Protective Devices Committee, 1996). To avoid these problems, electromagnetic transient analyses are usually done during equipment specification task when circuit breakers and other switching equipment are chosen. So, electromagnetic studies are prepared only after RC is already defined. In this paper, it is suggested these studies to be started in a very previous stage, in the evaluation step of expansion plans preparation. This procedure allows the selection of a better alternative in terms of transient impact on power system behavior. In conjunction with the detailed analysis prepared during substation project, it is expected that the final specified RC presents technical and economical advantages.

The short circuit calculations normally prepared in step (iii) simply verify if the RC reactive power is smaller than $5 \%$ of the system short circuit power. A relevant aspect to be noted is that this calculation does not guarantee that overvoltage and overcurrent values caused by capacitors bank switching are inferior to maximum permitted limit. This is shown in item 4.

The inclusion of transient analysis in planning procedure, not only in project specification, requires the identification of critical system areas and, if it is necessary, the modification of the original suggested RC alternative. This is not 
a trivial task, mainly in large systems. The complexity of this subject and the lack of planning strategies that include switching overvoltage and overcurrent analysis motivate the investigation reported in this work.

\section{CRITICAL BUSES RELATED TO ELEC- TROMAGNETIC TRANSIENTS}

In order to evaluate different $\mathrm{RC}$ alternatives regarding transient effects, many simulations must be prepared considering the capacitors switching possibilities (energization and de-energization). In large power systems, the evaluation of several network configurations constitutes a very laborious and time-consuming task, sometimes making the study impracticable. Additionally, the analysis of all the cases would include unnecessary simulation.

In this work, a technique that identifies the so-called "critical buses" is proposed. Such identification allows knowing which bus has the highest overvoltage or overcurrent in the energization or de-energization of a specific capacitor bank. The technique is used to classify the buses in accordance with system configuration: size of the switched capacitor, load characteristics, electrical distance of the source, installed equipment and other aspects (Coury et alii, 1998; Jota and Islan, 1998; McGranaghan et alii, 1992; Saied, 2004; Surge Protective Devices Committee, 1996).

The proposed method is based on the determination of indices that consider the coefficients of reflection $\left(\mathrm{R}_{F L}\right)$ and refraction $\left(\mathrm{R}_{F R}\right)$ of the system, as Greenwood (1991). In this paper, the methodology is applied only to identify the critical buses in terms of overvoltage aspect.

The analysis is made in a local form, considering the system as simple as possible, in such a way that the calculated indices give a notion of the overvoltage caused by transients. To compute these indices, voltage source is considered an unitary step, adopting short spaces of time.

With the objective of exemplify the proposed process, the simple circuit of 5 buses and 4 branches, illustrated in Figure 1 , is adopted. Resistive loads have been considered, in order to simplify the analysis of the reflection and refraction coefficients. The respective values for the impedances $\mathrm{Z}_{1}, \mathrm{Z}_{2}, \mathrm{Z}_{3}$ and $\mathrm{Z}_{4}(\mathrm{ohm})$ are 1.0, 2.0, 1.5 and 0.5, respectively. Propagation time $(\tau)$ has been assumed as $1 \mu$ s for $Z_{1}$ impedance line and $5 \mu$ s for the other ones.

The analysis involves two coefficient matrices $(\mathrm{C}, \mathrm{D})$, dimension $(4 \times 2)$, as seen in table 1 , where overvoltage values are related to the example system. In matrix $\mathrm{C}$, the coefficients of points $\mathrm{N}_{0}$ (source), $\mathrm{N}_{2}, \mathrm{~N}_{3}$ and $\mathrm{N}_{4}$ (loads) are inserted. In matrix $\mathrm{D}$, coefficients related to point $\mathrm{N}_{1}$ are placed in this

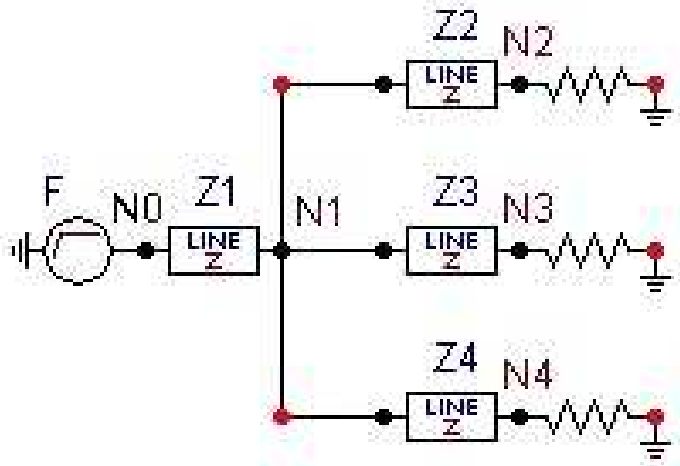

Figure 1: Circuit for coefficients RFL e RFR study.

way: the value calculated for each impedance $\left(Z_{1}, Z_{2}, Z_{3}\right.$, $\mathrm{Z}_{4}$ ) considers the equivalent as viewed from each one. The source is considered a short circuit whereas its internal reactance is admitted null. In these matrices, the first column represents the refraction coefficients and the second column contains the reflection coefficients.

Table 1: Refraction and reflection coefficients for the system of Figure 1.

\begin{tabular}{|c|c|c|c|c|c|}
\hline Matrix C & $\begin{array}{c}\mathbf{1} \\
\left(\mathbf{R}_{F R}\right)\end{array}$ & $\begin{array}{c}2 \\
\left(\mathbf{R}_{F L}\right)\end{array}$ & Matrix D & $\begin{array}{c}\mathbf{1} \\
\left(\mathbf{R}_{F R}\right)\end{array}$ & $\begin{array}{c}\mathbf{2} \\
\left(\mathbf{R}_{F L}\right)\end{array}$ \\
\hline No & 0 & -1 & $\mathbf{Z 1}$ & 0.48 & -0.52 \\
\hline N2 & 0.667 & -0.333 & $\mathbf{Z 2}$ & 0.24 & -0.76 \\
\hline N3 & 0.8 & -0.2 & $\mathbf{z 3}$ & 0.32 & -0.68 \\
\hline N4 & 1.333 & 0.333 & $\mathrm{Z4}$ & 0.96 & -0.04 \\
\hline
\end{tabular}

The overvoltage value depends on the coefficients just calculated and on the wave propagation time. This time has been neglected by the proposed methodology. The consideration of all reflections (or propagation time) in each point of the circuit would result in extremely complex calculations, similar to the complete transient simulation for all buses. Moreover, in fact, its consideration would not introduce great difference in index value, because a small parcel of the original wave would be added to each reflection.

The suggested index $\left(\mathrm{C}_{\text {itotal }}\right)$ consists of the sum of the following terms: first refracted wave in the load $\left(\mathrm{FR}_{L}\right)$, reflected wave in point $\mathrm{N}_{1}\left(\mathrm{FL}_{N 1}\right)$, reflected wave in source $\left(\mathrm{FL}_{S}\right)$ and refracted wave by the loads in point $\mathrm{N}_{1}\left(\mathrm{FR}_{N 1}\right)$ (equation (1)). The biggest value of index $\left(\mathrm{C}_{\text {itotal }}\right)$ indicates where, in the system, the highest overvoltage occurs, that is, it shows the critical bus. 


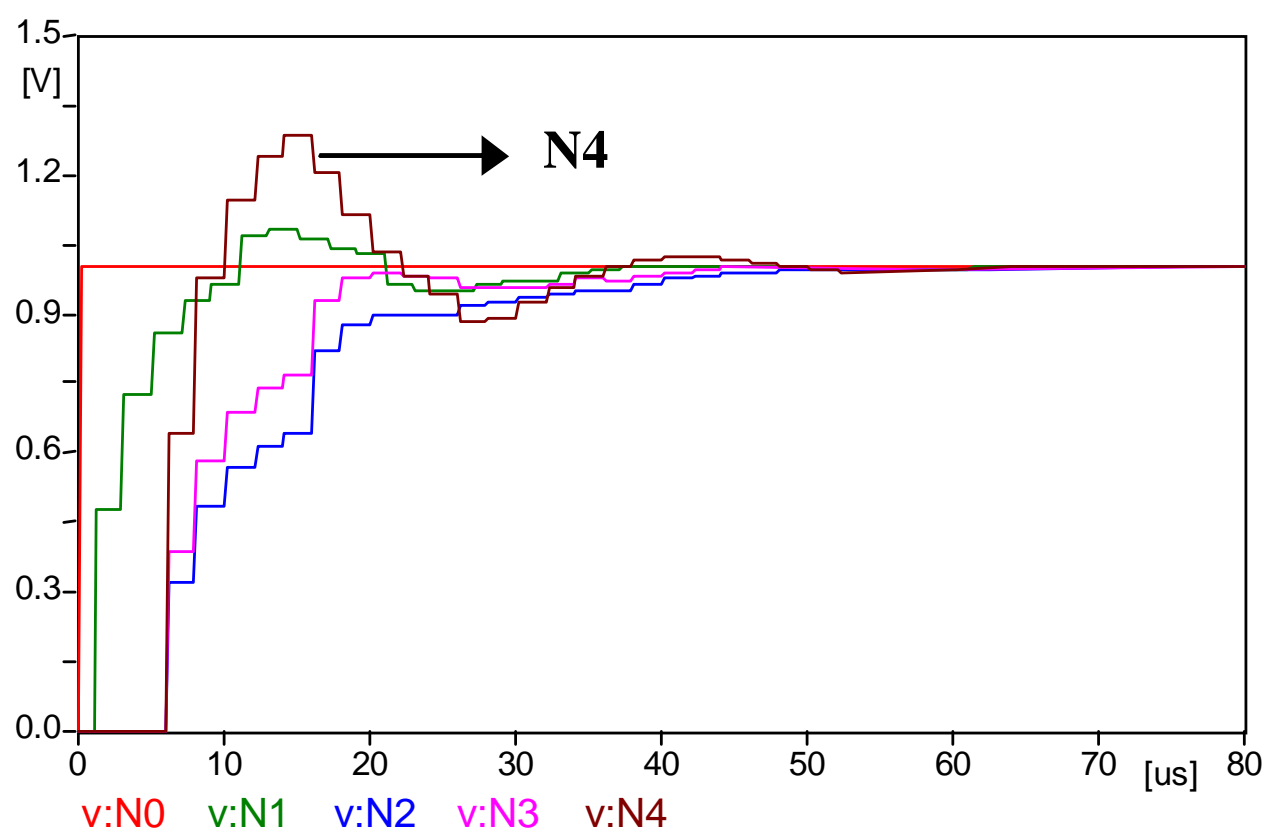

Figure 2: Voltage values in each point of Figure 1 circuit.

$$
C_{i t o t a l}=F R_{L}+F L_{N 1}+F L_{S}+F R_{N 1}
$$

$\mathrm{FR}_{L}$ is composed by the wave that comes from source, surpasses point $\mathrm{N}_{1}\left(\mathrm{~d}_{11}\right)$ and refracts in the load $\left(\mathrm{c}_{i 1}\right)$. $\mathrm{FL}_{N 1}$ is a wave $\mathrm{FR}_{L}$ that reflects in load $\left(\mathrm{c}_{i 2}\right)$, later in point $\mathrm{N}_{1}\left(\mathrm{~d}_{i 2}\right)$ and refracts in load $\left(\mathrm{c}_{i 1}\right) . \mathrm{FL}_{S}$ is the wave that does not cross point $\mathrm{N}_{1}\left(\mathrm{~d}_{12}\right)$, reflects in source $\left(\mathrm{c}_{12}\right)$ and, after that, goes beyond point $\mathrm{N}_{1}\left(\mathrm{~d}_{11}\right)$ and refracts in load $\left(\mathrm{c}_{i 1}\right)$. $\mathrm{FR}_{N 1}$ is the wave that, after reflecting in other loads $\left(\mathrm{c}_{j 2}\right)$, it passes point $\mathrm{N}_{1}$ in direction to the desired load $\left(\mathrm{d}_{j 1}\right)$ and refracts in this load $\left(\mathrm{c}_{i 1}\right)$. The $\mathrm{i}$ and $\mathrm{j}$ pointers of the coefficient matrices $\mathrm{C}$ and $\mathrm{D}$ are always greater than 1 . The goal becomes to verify $\mathrm{C}_{\text {itotal }}$ in loads. Equation (2), derived from equation (1), explains what is dealt with in this paragraph.

$C_{i t o t a l}=\left[1+c_{i 2} \cdot d_{i 2}+d_{12} \cdot c_{12}+\sum_{j \neq i}^{n} c_{j 2} \cdot d_{j 1}\right] \cdot d_{11} \cdot c_{i 1}$

To validate this index, several tests are prepared. Considering the example system, the obtained indices for points $\mathrm{N}_{2}$, $\mathrm{N}_{3}$ and $\mathrm{N}_{4}$ are, respectively, $0.65,0.73$ and 0.87 . Point $\mathrm{N}_{4}$ reaches the highest overvoltage (Figure 2) and the maximum index value, so confirming the critical bus detection.

\section{ELECTROMAGNETIC TRANSIENTS - EVALUATION OF REACTIVE COMPEN- SATION PLAN}

The proposed procedure for technical evaluation of RC alternatives, in terms of electromagnetic transient aspects, consists of distinct analyses: energization and de-energization of the first and second capacitor banks. The procedure steps, described below, and the flowchart of this evaluation are presented in Figure 3.

\section{i. Suggested Reactive Compensation}

This step is related to the procedure input data, which inform about the $\mathrm{RC}$ alternative to be evaluated.

\section{ii. Critical Buses}

The critical bus has the highest index $\mathrm{C}_{i t o t a l}$, as explained in item 2. In this step, the buses that have the highest overvoltage and overcurrent are identified and, for them, simulations are made.

\section{iii. Equipment Modeling}

From this step ahead, two types of distinct analyses are developed: switching of the first and second bank. In both analyses, the dispersion effect among breaker contacts is considered and the surge arrester limits are represented. In this work, the models adopted for system components are the traditional ones, as described in references Greenwood (1991) e D’Ajuz (1987). 


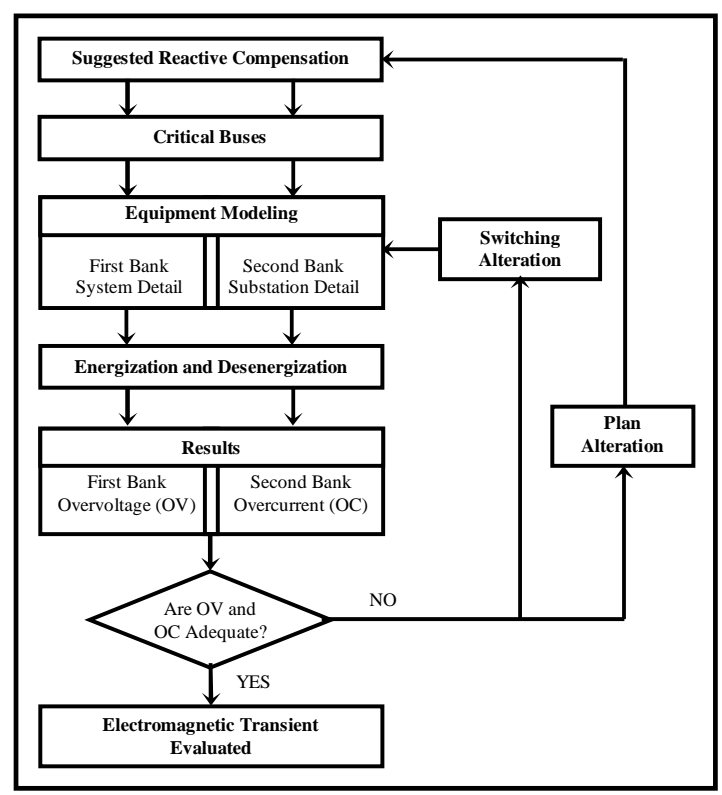

Figure 3: Expansion Technical Evaluation - Electromagnetic Transient.

(a) Analysis 1 - First Bank

The main goal of this analysis is to evaluate the overvoltage caused by a single bank switching, placed in a bus. The simulation considers three adjacent buses to this bank.

(b) Analysis 2-Second Bank

This analysis evaluates the overcurrent caused by the second bank switching (back-to-back configuration). The substation, where the capacitor is located, is modeled in this study. Equivalents are prepared to represent other system equipment.

iv. Energization and De-energization

In this step, simulations are realized considering energization and de-energization of the first and second banks. Adopting the adequate circuit modeling for each analysis, overvoltage and overcurrent resultant from capacitor switching are determined. Measurements are prepared for the capacitor, load and near sensible equipment. Energy absorbed by the surge arrester is also measured. In the de-energization analysis, breaker restrike is considered (Das, 2005; Grebe and Gunther, 1998; McGranaghan et alii, 1992). An electromagnetic transient software may be used for simulations.

\section{v. Results}

Reports and graphs are generated to present overvoltage values $(\mathrm{OV})$ related to first bank simulations and overcurrent values (OC) to the second. vi. Are OVand OC adequate?

$\mathrm{OV}$ and $\mathrm{OC}$ must be inferior to the maximum value supported by the equipment near capacitor (Sabin et alii, 1999). It must be verified if the surge arrester supports the produced energy at the moment capacitor switching occurs, in order to avoid the risk of this equipment to burn or to open the circuit (Grebe and Gunther, 1998; McGranaghan et alii, 1992). It is also evaluated if the capacitor switching can make unused some circuit element or cause any alteration in the normal operation of sensible equipment. Such limits depend on the installed equipment and the number of capacitor switchings realized during the year.

\section{vii. Plan Alteration}

If some restriction is not respected, it is necessary to modify the suggested RC expansion plan. The procedure that indicates the adequate modifications considers the evaluation of different options:

(a) Alteration of the number of capacitors, without modifying the amount of reactive power placed in the bus. Different load conditions (light, average and heavy) are considered in simulations.

(b) Substitution of the initially proposed capacitor by another equipment with more adequate switching behavior.

(c) Selection of one or more buses to have their reactive compensation modified or eliminated. To select these buses, a sensitivity analysis is used to identify the so-called "candidate bus". The candidate bus is the one that has more influence over the critical bus (detected by transient simulations), regarding voltage control and reactive compensation. The amount of reactive power is partially or integrally transferred from the critical bus to the candidate one.

In this process, it is very important to consider $\mathrm{C}_{\text {itotal }}$ values, to avoid choosing a bus that is inadequate regarding transient aspects. Reactive power must be dislocated towards buses with smaller indices $\mathrm{C}_{\text {itotal }}$ to prevent overvoltage and overcurrent increases.

viii. Switching Type Alteration

An additional alternative to avoid transient problems is the indication of a capacitor switching type in such a way to reduce transient overvoltage and overcurrent. Controlled switching or preinsertion resistance or reactor may be used. Controlled switching is recommended because it does not introduce electric losses and avoids breaker damage (Bhargava et alii, 1993; Das, 2005; Fernandez et alii, 2004; Grebe and Gunther, 1998). 


\section{SIMULATION RESULTS}

The selected power system is a real network of 19 buses and ATPDraw, a commercial program, is used for electromagnetic transient calculations.

Before showing results related to the use of transient analyses to decide about adequate $\mathrm{RC}$ definition, it is interesting to discuss about the short circuit criterion mentioned in item 1. Table 2 presents some simulation results showing that this criterion does not guarantee overvoltage values, caused by capacitors bank switching, to be inferior to maximum permitted limit. In this table, "RCmax" indicates the maximum Mvar values according to short circuit evaluation (5\% of system short circuit power). "RC" contains the Mvar values proposed by the optimization process and "OV RC" shows the overvoltages for each bus. One can see that, even inferior than those pointed by short circuit criterion, the proposed "RC" may not attend transient limits (1.80 pu, in this example). This fact emphasizes the importance of including transient analyses in planning evaluating step (iii).

Table 2: Reactive compensation and overvoltage values.

\begin{tabular}{|c|c|c|}
\hline $\begin{array}{c}\text { RCmax } \\
(\text { Mvar })\end{array}$ & $\begin{array}{c}\text { RC } \\
\text { (Mvar) }\end{array}$ & $\begin{array}{c}\text { OV RC } \\
(\mathrm{pu})\end{array}$ \\
\hline 18.9 & 6.2 & 1.89 \\
\hline 27.7 & 0.5 & 1.84 \\
\hline 25.2 & 24.2 & 1.77 \\
\hline 27.0 & 17.5 & 1.85 \\
\hline
\end{tabular}

The optimization process suggests the initial shunt compen- sation. For the $13.8 \mathrm{kV}$ buses, it indicates the use of 2.4 and 4.8 Mvar capacitors. Three buses with very distinct characteristics are chosen to identify the critical bus. Their loads are 16.6 MVA, 20 MVA and 71.2 MVA. Two capacitors of 4.8 Mvar are proposed for the first bus, a 2.4 Mvar capacitor for the second and a 4,8 Mvar capacitor for the last one. There is an additional 75.4 MVA load near the second bus. The lines that supply energy for these loads are $50 \mathrm{~km}, 100 \mathrm{~km}$ and $200 \mathrm{~km}$ in length, respectively.

The calculated overvoltage indices $\left(\mathrm{C}_{\text {itotal }}\right)$ of the three buses are 1.61, 1.46 and 1.26. The critical bus is the first one that has the biggest index and light load. Figure 4 presents the voltage values of the simplified system composed by these buses. It is confirmed that the biggest overvoltage occurs in bus 1 , represented by letter B. Letter S represents the voltage in the source. The critical bus, in terms of overcurrent, coincidentally is the same bus.

For the first capacitor bank, system is modeled in a macro way (system level - adjacent buses are considered):

- Source model: equivalent voltage source (Vth);

- Transmission line model: transposed three-phase line; zero and positive sequence data; line length;

- Load model: three-phase linear element; resistive and inductive components;

- Capacitor model: three-phase linear element; capacitive parameter;

- Circuit breaker model: simultaneous three-phase switching in the peak value of one of the phases (simple model);

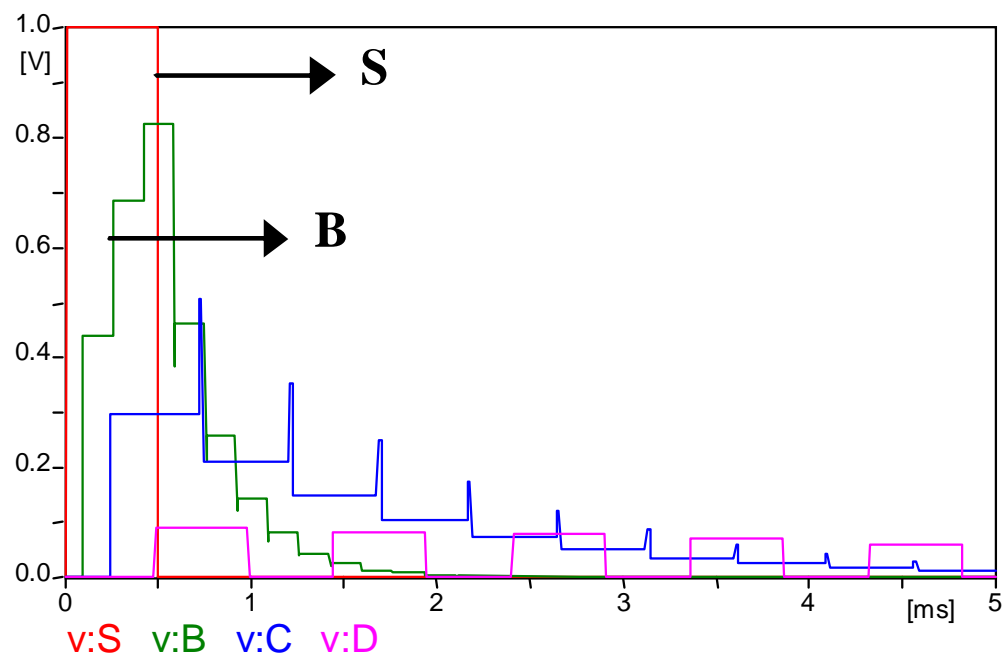

Figure 4: Critical Bus Identification. 
- Transformer model: three-phase two-winding saturated transformer; wye-delta connection with grounded neutral.

For the second bank, system is modeled in a micro way (substation level):

- Source model: equivalent voltage source (Vth);

- Transmission line model: equivalent three-phase line;

- Load model: three-phase linear element; resistive and inductive components;

- Capacitor model: three-phase linear element; resistive and capacitive components;

- Circuit breaker model: simultaneous three-phase switching in the peak value of one of the phases (simple model);

- Busbar and conductor model: three-phase linear element; resistive and inductive components;

- Transformer model: three-phase two-winding saturated transformer; wye-delta connection with grounded neutral.

Energization and de-energization of the first and second banks are completely simulated but, in the present paper, it is shown only energization results and the respective plan alteration.

The first bank energization (4.8 Mvar) generates an overvoltage of 1.86 pu that can be confirmed by the graph depicted in Figure 5 (a). Transient remains approximately by $61 \mathrm{~ms}$. Considering that capacitor switching is realized 400 times per year, the voltage limit to be adopted for the capacitor is 1.80 pu by $50 \mathrm{~ms}$. Therefore, the expansion plan alteration becomes necessary.

In the second 4.8 Mvar bank, the overcurrent is 5.72 pu (Figure 5 (b)) and the transient remains approximately by 180 $\mathrm{ms}$. It is adopted a typical limit of $4.0 \mathrm{pu}$ during $1 \mathrm{~s}$. Then, it becomes necessary to modify the plan.

An option for planning modification would be to maintain the Mvar amount and localization suggested by the steady state optimization process, but changing the number of capacitors placed in the critical bus.

This procedure is done for the case study, using a 9.6 Mvar capacitor instead of two of 4.8 Mvar. In this new configuration, the system presents a lower overcurrent, due to the fact that it is not necessary to energize the second bank. However,

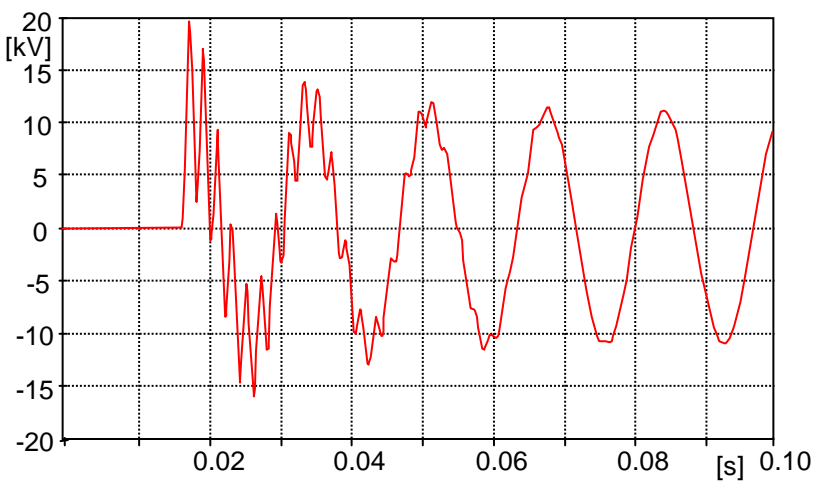

(a)

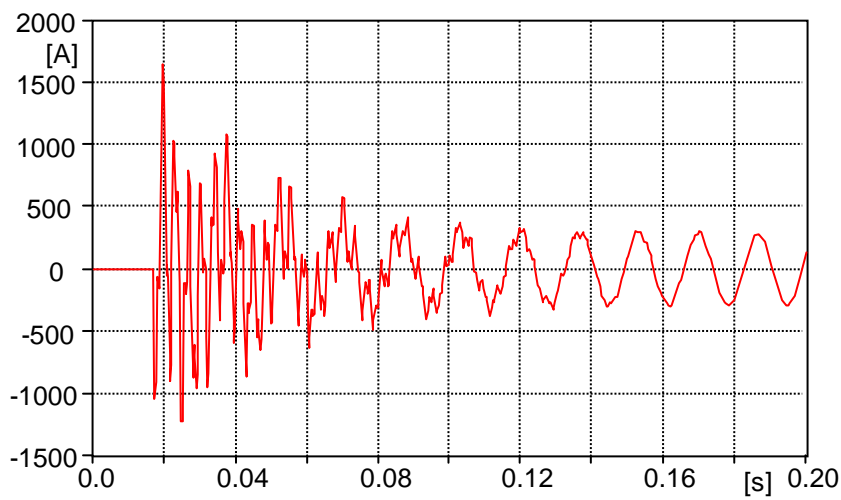

(b)

Figure 5: (a) Voltage transient in energization of first bank; (b) overcurrent transient in energization of second bank.

the overvoltage increases to 1.89 pu during $89 \mathrm{~ms}$, denoting that problem is not solved.

Another option is to indicate, by a sensitive analysis, a candidate bus to receive partially or totally the compensation. This bus is that with the heaviest load and lowest transient index. In the case study, it is added $8.4 \mathrm{Mvar}$ in the candidate bus, remaining only 1.2 Mvar in the critical bus. Here, again, it is not necessary to energize the second bank. The critical bus overvoltage diminishes to $1.75 \mathrm{pu}$, remaining by $69 \mathrm{~ms}$, and the candidate bus overvoltage reaches 1.55 pu by a period of $25 \mathrm{~ms}$. Both overvoltages are within the limit considered acceptable.

Beyond these two alternatives, a third option, regarding switching type is simulated. The transients related to one phase are seen in Figures 6 and 7. Using the Controlled switching, it is verified (Figure 6 (a)) that the overvoltage diminishes to $1.23 \mathrm{pu}$, lasting $57 \mathrm{~ms}$. It is confirmed by Figure 7 (a) that overcurrent decreases to $3.64 \mathrm{pu}$, remaining by $300 \mathrm{~ms}$. With the use of a preinsertion reactor, the overvoltage reduces to $1.52 \mathrm{pu}$ (Figure 6 (b)), persisting by $29 \mathrm{~ms}$, while the overcurrent is $1.96 \mathrm{pu}$, lasting $21 \mathrm{~ms}$ (Figure 7 (b)). 


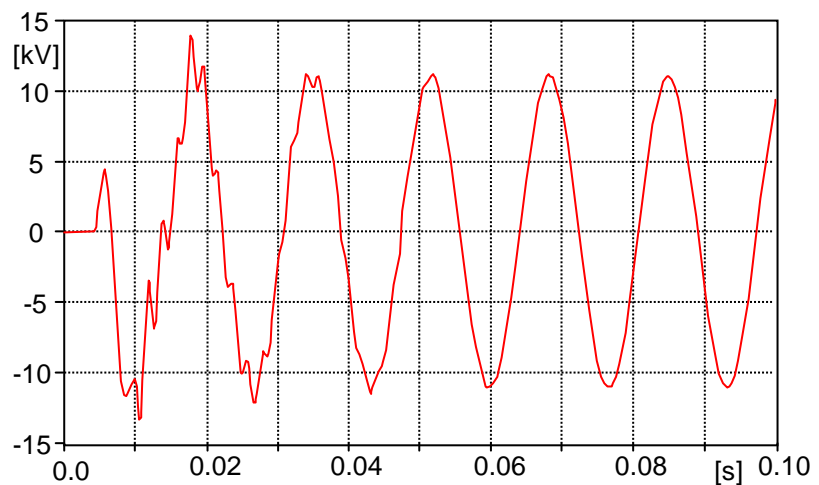

(a)

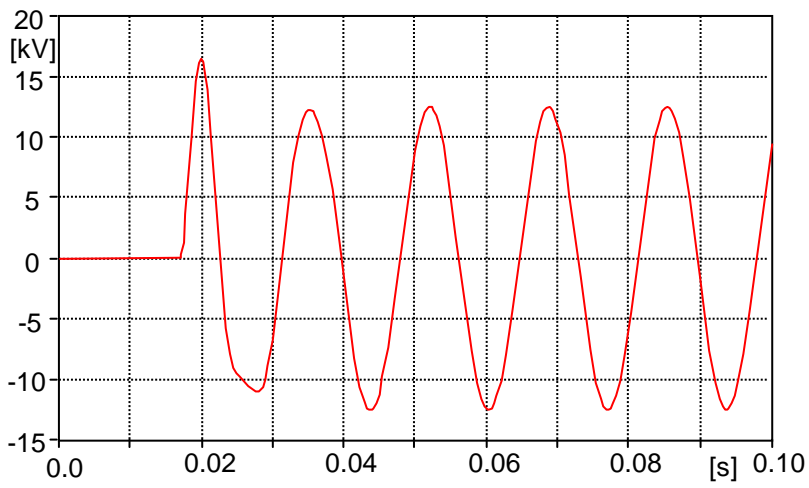

(b)

Figure 6: Overvoltage transient in the first bank energization (a) with synchronized switching; (b) with preinsertion reactor.

With the switching type modifications, the overvoltage and overcurrent limits are respected and their magnitudes are smaller than those obtained with compensation change procedure. Nevertheless, additional cost and insertion of electric losses are expected. The planner must ponder over the possibilities, considering electrical and economic aspects, in order to choose the most appropriate solution.

The example treated in this paper dealt with only the switched capacitor limits. However, the restrictions could be related to an equipment installed near the compensation or to a surge arrester that could not support the transient energy, burning or opening the circuit. For these cases, the procedure for expansion planning alteration follows the same steps, modifying only the limit to be observed.

\section{CONCLUSIONS}

This work presents a strategy to prepare the technical evaluation of expansion alternatives for reactive compensation in the aspects of electromagnetic transient. The importance to verify the overvoltage and overcurrent originated from

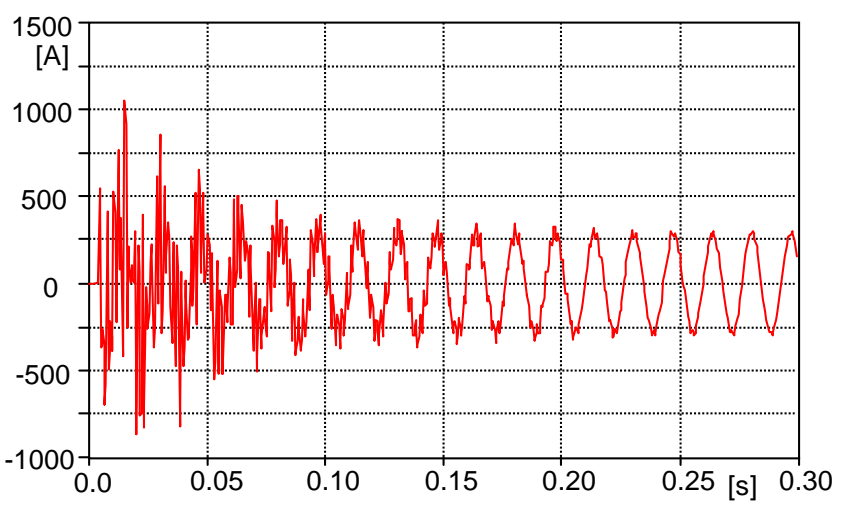

(a)

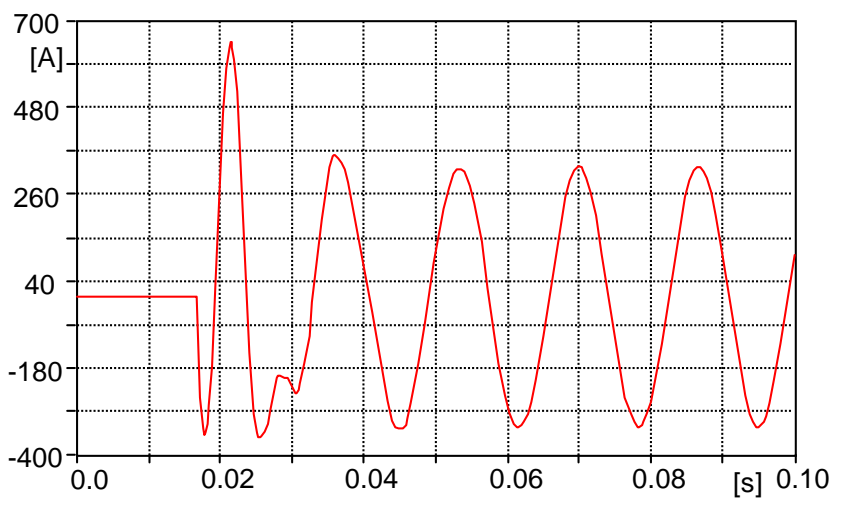

(b)

Figure 7: Overcurrent transient in the second bank energization (a) with synchronized switching; (b) with preinsertion reactor.

capacitor switching is confirmed by the obtained results. Capacitor transients can provoke irreparable damages into equipment and deteriorate system performance. A previous and careful analysis prepared during planning stage, not only during equipment final specification, can avoid serious critical situations to power systems.

If the planning evaluation step points out that the suggested RC alternative is not satisfactory, it must be modified. The $\mathrm{RC}$ plan alteration can be done by changing the amount and localization of the capacitive compensation or by modifying the capacitor switching type. Each option has its properties, remaining to the planner the selection of the most adequate one. In very specific cases such modifications are not viable and another expansion alternative (new transmission line, substations and others) should be investigated.

In this paper, it is introduced an innovative concept of critical buses applied to reactive shunt compensation considering electromagnetic transient aspects. The critical buses are used to make it possible for planners to calculate and analyze expansion alternatives. It is also proposed an index for buses 
classification that indicate those with high overvoltage and overcurrent. By the obtained results, it is confirmed that the application of these indices is valid and important for reactive compensation choice.

\section{REFERENCES}

Bhargava, B., A.H. Khan, A.F. Imece, and J. Di Pietro (1993). Effectiveness Of Pre-Insertion Inductors For Mitigating Remote Overvoltages due To Shunt Capacitor Energization. IEEE Transactions on Power Delivery, Vol. 8, No. 3, pp. 1226-1238.

Chaves, F.S. (2001). Technical Procedure Applied to Reactive Compensation and Voltage Control in Electric Power Systems (in Portuguese). MSc. Dissertation, Supervisor: M.H.M. Vale, LRC/PPGEE - Federal University of Minas Gerais, Brazil.

Chaves, F.S. and M.H.M. Vale (2002). Voltage Control and Reactive Compensation - Technical Procedure Applied to Power System Expansion (in Portuguese). XIV CBA, Natal - Brazil.

Chaves, F.S. (2007). Technical Evaluation of the Capacitive Shunt Reactive Compensation Performance Applied to Electric Power System Expansion (in Portuguese). Ph.D. Dissertation, Supervisor: M.H.M. Vale, LRC/PPGEE - Federal University of Minas Gerais, Brazil.

Coury, D.V., C.J. Santos and M.C. Tavares (1998). Transient Analysis Resulting from Shunt Capacitor Switching in an Actual Electrical Distribution System. $8^{\text {th }}$ International Conference on Harmonics and Quality of Power ICHQP'98 (IEEE), Athens - Greece, pp. 292-297.

D'Ajuz, A., C.S. Fonseca, F.M.S. Carvalho, J. Amom Filho, L.E.N. Dias, M.P. Pereira, P.C.V. Esmeraldo, R. Vaisman, and S.O. Frontin (1987). Electric Transients and Insulation Coordination - Application in High-voltage Power Systems (in Portuguese). Fluminense Federal University, Rio de Janeiro - Brazil.

Das, J.C. (2005). Analysis and Control of Large-ShuntCapacitor-Bank Switching Transients. IEEE Transactions on Industry Applications, Vol. 41, No. 6, pp. 14441451.

Fernandez, P.C., P.C.V. Esmeraldo, J. Amom Filho, and C.R. Zani, (2004). Use of Controlled Switching Systems in Power System to Mitigate Switching Transients. Experience Trends And Benefits - Brazilian. IEEE/PES Transmission \& Distribution Conference \& Exposition: Latin America, pp. 85-90.
Grebe, T.E. and E.W. Gunther (1998). Application of the EMTP for Analysis of Utility Capacitor Switching Mitigation Techniques. $8^{\text {th }}$ International Conference on Harmonics and Quality of Power ICHQP'98 (IEEE), Atenas - Greece, pp. 583-589.

Greenwood, A. (1991). Electrical Transients in Power Systems, $2^{\text {nd }}$ Edition, John Wiley \& Sons, Inc..

Jota, P.R.S. and S.M. Islam (1998). Effect of Realistic System Modelling on Low-Voltage Capacitor Transient Overvoltages. IEE Proceedings Generation, Transmission \& Distribution, Vol. 145, No. 6, pp. 682-686.

McGranaghan, M.F., R.M. Zavadil, G. Hensley, T. Singh, and M. Samotyj (1992). Impact of Utility Switched Capacitors on Customer Systems - Magnification at Low Voltage Capacitors. IEEE Transactions on Power Delivery, Vol. 7, No. 2, pp. 862-868.

Sabin, D.D., T.E. Grebe, D.L. Brooks, and A. Sundaram (1999). Rules-Based Algorithm for Detecting Transient Overvoltages due to Capacitor Switching and Statistical Analysis of Capacitor Switching in Distribution Systems. IEEE, pp. 630-635.

Saied, M. (2004). Analysis of the Amplitude and Frequencies of the Voltage Magnification Transients in Distribution Networks due to Capacitor Switching. IEEWPES Transmission CL Distribution Conference \& Exposition: Latin America, pp. 34-38.

Surge Protective Devices Committee (1996). Impact of Shunt Capacitor Banks on Substation Surge Environment and Surge Arrester Applications. Report by Working Group 3.4.17 of the IEEE Transactions on Power Delivery, Vol. 11, No. 4, pp. 1798-1809.

Vale, M.H.M., F.S. Chaves, J.R. Valadares, and A.N. Cortez (2005). Reactive Compensation and Voltage Control - Expansion Technical Evaluation in Voltage Stability Aspects (in Portuguese). XI ERIAC, Hernandarias - Paraguay. 